Estudios Geográficos, LXIX, 265, pp. 577-607, julio-diciembre 2008

ISSN: 0014-1496

elSSN: $1988-8546$

doi: 10.3989/estgeogr.0425

\title{
El sudeste andaluz: incertidumbres comerciales de una agricultura productivista
}

\author{
Southeastern Andalucia: comercial uncertainties \\ of a productivist agricultura
}

\section{Remedios Larrubia Vargas*}

La especialización productiva del sudeste andaluz ${ }^{1}$ ha permitido identificarlo como un distrito hortofrutícola haciendo extensivo a este modelo de organización de base agraria el concepto de distrito industrial. La realidad es que hay muchos elementos que apoyan esta identificación, como comentaremos en primer lugar.

La debilidad de este ejemplo específico de distrito productivo es su especialización hortofrutícola, mayoritariamente de carácter productivista, ya que debido a sus elevados inputs es sumamente dependiente de los mercados y de las cotizaciones. Este es el punto central que se pretende analizar: revisar los márgenes reales de las producciones y contrastarlos con las perspectivas del nuevo escenario que se va dibujando para la comercialización agraria europea.

* Departamento de Geografía, Universidad de Málaga (rlarrubia@uma.es).

1. El sudeste andaluz, área geográfica que constituye el objeto del presente trabajo, es una amplia zona que comprende las comarcas agrarias del Guadalhorce y Vélez-Málaga en la provincia de Málaga, la comarca de La Costa en la de Granada y las comarcas del Campo de Dalías, Campo de Níjar-Bajo Andarax y Bajo Almanzora en la provincia de Almería. Cada una de estas comarcas se ha especializado en unos productos hortofrutícolas concretos, de forma que en función del producto que se analice se aludirá al espacio concreto donde más intensamente se desarrolla. 


\section{EL SUDESTE ANDALUZ, UN DISTRITO PRODUCTIVO HORTOFRUTÍCOLA}

El sistema de producción hortofrutícola del Poniente Almeriense, que en un proceso de desbordamiento geográfico inundó las llanuras y laderas costeras de las provincias de Granada y Málaga, constituye un modelo de crecimiento económico singular a partir de la agricultura y ha sido considerado como un sistema productivo local (Ferraro, 2000) y como un distrito agroindustrial-agrocomercial (Caldentey y Gómez, 1996).

El tema de los distritos industriales fue enunciado por primera vez por el economista británico Alfred Marshall en 1919, cuando enunció las ventajas de la producción a gran escala, agrupando en un mismo distrito a un gran número de pequeños productores o construyendo pocos grandes talleres. Pero dicho concepto quedó en el olvido hasta que fue recuperado a finales de los años setenta por economistas y sociólogos italianos que lo replantearon de nuevo, entre los que destacan Giacomo Becattini quien define al distrito industrial como una entidad socioterritorial que se caracteriza por la presencia activa de una comunidad de personas y como un conjunto de empresas en una zona natural e históricamente determinada (Becattini, 1989, 1996, 2002 y 2006).

Climent López (1997) considera que para que exista distrito industrial no solamente se tiene que producir una concentración de empresas en un lugar concreto, sino que en esa concentración se debe dar tres condiciones necesarias: que no exista ninguna empresa que controle o domine la producción local (entonces estaríamos ante una Red de Empresas), tan sólo empresas relacionadas entre sí por vínculos mercantiles y no mercantiles sin que domine ninguna de ellas (Caldentey, 2002); que las empresas pertenezcan mayoritariamente a la misma rama de actividad, entendida como un conjunto de actividades productivas conectadas entre sí, aunque sus productos y procesos sean de distinta naturaleza, a lo que también se añade los servicios estrechamente vinculados con dichas actividades productivas; que las empresas del distrito estén fuertemente especializadas en fases concretas de la producción.

A las características anteriores Caldentey (1998) añade que la actividad dominante haya superado el mercado local y destine la producción prioritariamente al mercado externo (nacional o internacional), que existan empresas auxiliares suministradoras de inputs y prestación de servicios, que existan relaciones de tipo vertical, horizontal y transversal entre empresas, que las empresas y las personas presenten un sentimiento de "identificación 
o de conciencia" de formar parte de un distrito o de una comunidad, que exista interés por la adopción de innovaciones, que sea frecuente la externalización de actividades y servicios por parte de las empresas, por contratación con otras empresas, etc. Según este autor el distrito industrial se presenta como alternativa a la red de empresas, siendo un sistema en el que se sustituye la empresa constituida en secciones o departamentos y una serie de empresas subcontratantes de aquellas por pequeñas empresas relacionadas entre sí por vínculos mercantiles y no mercantiles sin que domine ninguna de ellas (Caldentey, 2002).

Desde hace más de 30 años, el sistema agrícola² desarrollado en el sudeste andaluz cumple mucha de las características marcadas para los distritos industriales. Se trata de un modelo de producción endógeno al aprovechar desde el principio recursos eminentemente locales, orientando posteriormente su producción al exterior, con importante incorporación de nuevas tecnologías que han permitido generar un proceso de desbordamiento positivo hacia actividades auxiliares (industrias y servicios auxiliares a la agricultura) que contribuyen indiscutiblemente en la competitividad del modelo, de forma que se ha pasado de un modelo exclusivamente agrario a un modelo agroindustrial, denominado así no tanto por la naturaleza de los productos salidos de las unidades de producción, que son predominantemente en fresco, sino por la variedad e intensidad de los inputs, la innovación y complejidad tecnológica, la comercialización, etc.

El sistema se configuró, por una parte, a través de una infraestructura de producción minifundista (1,3 hectárea de media), con una necesidad de mano de obra elevada (2-2,5 jornales/ha/año) que en sus inicios se cubría con mano de obra familiar, pero que en la actualidad acoge no sólo a trabajadores ajenos a la explotación sino al propio territorio (inmigración). Por otra parte, se configuró en base a un sistema de comercialización bastante precario, con gran dependencia de agentes comerciales externos. A partir de estas bases iniciales el modelo ha ido evolucionado mediante la incorporación de tecnología productiva e innovación, tanto en la fase de producción como en la de postproducción (organización comercial).

En la fase de producción, una de las primeras y más espectaculares innovaciones tecnológicas producida en la agricultura intensiva de alto

2. La producción científica en relación al sistema agrario desarrollado desde finales de la década de los años sesenta en el sudeste andaluz es muy destacada, tanto en número como en calidad; al respecto podemos señalar a distintos autores: Calatrava Requena, J. (1982, 1985), García Lorca, A. (1980, 1985, 1999), García Manrique, E. (1972, 1984), Hernández Porcel, M. C. (1978, 1987), etc. 
rendimiento fue la técnica del enarenado (García, 1984), tecnología cuyo inicio se sitúa en la zona limítrofe de las provincias de Almería y Granada (municipios de La Rábita y el Pozuelo) allá por el año 1880, cuando algunos agricultores de la zona se dieron cuenta de que protegiendo los cultivos con una capa de arena aumentaban las producciones y se adelantaba la época de recolección. En el momento actual, debido a los problemas económicos (excesiva inversión anual y plurianual) y agronómicos que este método genera, está siendo sustituido por el cultivo en sustrato, utilizándose como soporte físico para las plantas la lana de roca, la perlita y la fibra de coco fundamentalmente (Molina y García, 2002), cuya evolución supone la aparición de los cultivos hidropónicos. En este proceso innovador, con posterioridad, se produce la unión entre las formas tradicionales de producción y los nuevos materiales mediante la construcción del primer invernadero piloto con plástico en el Campo de Dalías (1961) bajo la dirección de técnicos del INC, aunque su difusión se retrasó hasta los años setenta. Conseguido el ambiente necesario para el desarrollo de las plantas, el siguiente paso fue las instalaciones de riego y fertirrigación, donde se ha pasado desde los tradicionales sistemas de riego por inundación a los actuales sistemas de riego localizados de alta frecuencia, o los de flujo continuo e intermitente en los sistemas hidropónicos puros. El proceso de innovación a nivel productor se completa con el material vegetal de propagación, los nutrientes y distintos promotores del crecimiento.

Como hemos apreciado, desde los primeros momentos fructifica la unión entre agricultura intensiva e industria transformadora del plástico. En los albores del sistema, estos materiales como otros, venían del exterior, pero en la década de los ochenta se inicia el montaje de fábricas de plástico en el Poniente Almeriense (Carretero, 2000), junto con otras de sistemas de riego, de cajas de envases y embalajes, de producción de semillas, etc.

En la fase de la postproducción también ha sido notable la evolución producida. El origen de la organización comercial estuvo basado en pequeñas subastas en las zonas de Roquetas de Mar y Vicar y en agentes comerciales extralocales. Esta situación fue transitoria y dio lugar a la aparición de las alhóndigas donde se vendía el producto mediante un sistema de subasta a la baja, y que además en un principio, ante la escasa infraestructura financiera que existía en la zona, asumieron los servicios de financiación a los agricultores. La falta de capacidad de las alhóndigas para abordar las iniciativas necesarias para la moderna distribución agroalimentaria favoreció la integración horizontal y vertical con la aparición, en la década de los setenta, de cooperativas agrarias y SAT (Sociedad Agraria de Transformación) 
con el objeto de aglutinar la producción en unidades de comercialización más grandes y controladas directamente por los socios (Larrubia, 1991). La última fase en esta organización ha sido, desde la incorporación de España a la Unión Europea y ante las exigencias de la OCM (Organización Común de Mercado), la constitución de unidades de comercialización más potentes (Organización de Productores de Frutas y Hortalizas).

El sistema comercial también lleva inherente intensos efectos multiplicadores sobre otras actividades, puesto que, además de la creación de un importante número de centrales de comercialización hortofrutícola (en la actualidad más de 375), hay que contemplar toda una serie de procesos intermedios de limpieza, selección, manipulación, normalización, envasado, almacenamiento y transporte de los productos desde el campo al almacén y desde éste hasta los centros de distribución.

Las interrelaciones productivas que genera la agricultura intensiva se completa con empresas de recogida y reciclaje, empresas de financiación, asesorías agronómicas, etc., que aparecen recogidas en la figura 1.

FIGURA 1. EFECTOS MULTIPLICADORES DE LA AGRICULTURA INTENSIVA

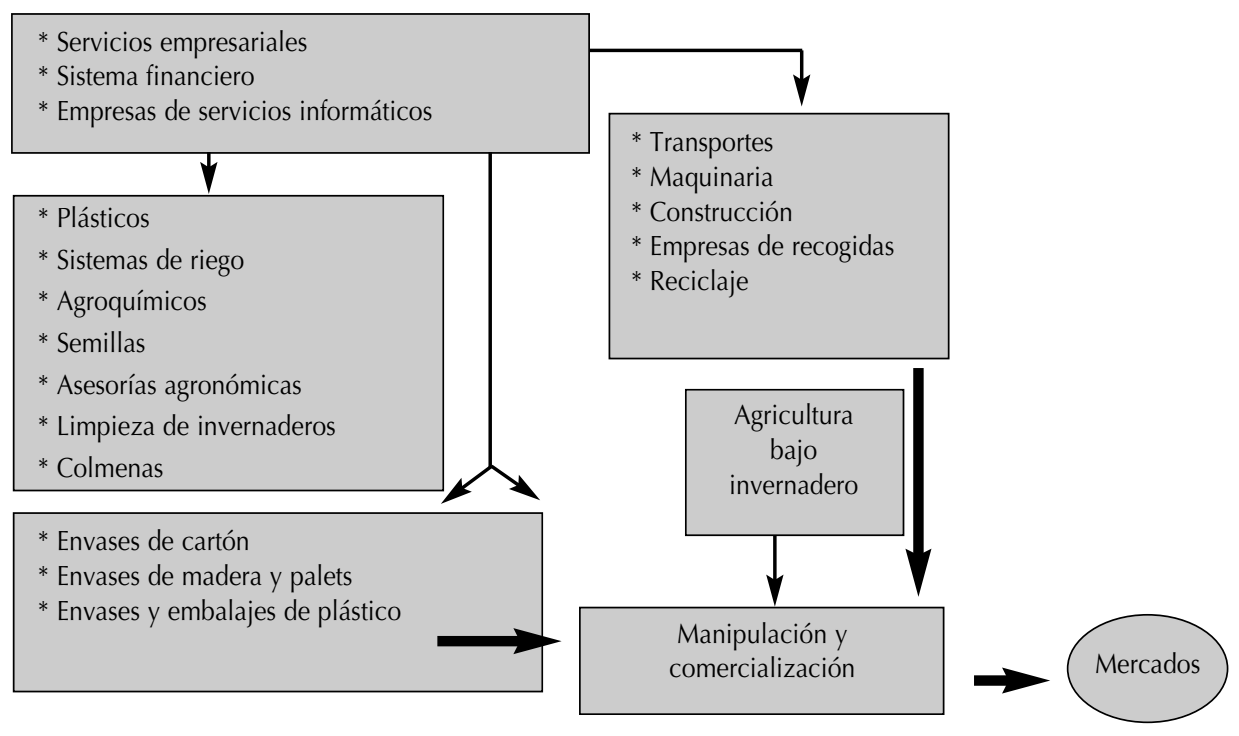

Fuente: Ferraro (2000).

Este sistema productivo que, como apreciamos, posee múltiples externalidades positivas también lleva implícito importantes implicaciones negativas (medioambientales, paisajísticas, socioeconómicas, etc.). En la fase de 
producción los impactos medioambientales reiteradamente señalados son la sobreexplotación de los acuíferos, su salinización y contaminación, la contaminación de suelos y aguas por fitosanitarios y fertilizantes, costes energéticos, etc. Desde el punto de vista paisajístico se menciona el impacto que genera la propia superficie invernada, junto a las grietas provocadas en el terreno para extraer la arena necesaria para el sistema de enarenado. En la fase de postproducción hay que citar la proliferación de residuos como plásticos, alambres, restos de vegetales y materiales de desechos de los almacenes de confección, además de la permanencia de residuos fitosanitarios sobre el producto que en muchas ocasiones han dificultado su comercialización.

Desde el punto de vista socioeconómico, la agricultura de vanguardia siempre ha sido valorada muy positivamente para las zonas donde se desarrolla, porque ha mejorado el nivel de vida de los habitantes, ha propagado el dinamismo económico, ha generado empleos directos e indirectos invirtiendo el tradicional proceso emigratorio, ha estabilizado la población y ha aportado sustanciosos ingresos a la balanza comercial. En la actualidad el modelo presenta debilidades: por un lado, el desequilibrio producido entre la oferta y la demanda de mano de obra agrícola local ha disparado la contratación de mano de obra inmigrante que, dejando de lado los importantes problemas sociales que genera, se apunta como negativo su baja cualificación; por otro lado, la aparición de rendimientos agrícolas decrecientes debido al incremento de los costes de producción que no han ido acompañados por un aumento proporcional, tanto de la productividad como de los precios de los productos hortofrutícolas.

\section{SITUACIÓN DEL SECTOR PRODUCTOR HORTOFRUTÍCOLA EN EL SUDESTE ANDALUZ}

\section{La producción hortofrutícola del sudeste andaluz en el contexto nacional}

La importancia del sector hortofrutícola del sudeste andaluz se puede apreciar a través de distintos parámetros, por su contribución a la producción final agraria, por su aportación en superficie y producción al total andaluz y español, por la importancia local que adquieren ciertas producciones que por su localización en zonas muy concretas constituyen un ejemplo de crecimiento económico a partir de la agricultura y, por último, por la independencia del sector respecto a los apoyos públicos, debido a su tradicional orientación al mercado, tanto interior como exterior. 
Como punto de partida hay que señalar que España es un gran productor y comercializador de frutas y hortalizas, la superficie dedicada a estas producciones gira en torno a 1,7 millones de ha, y 24 millones de toneladas (cuadro 1). Este volumen productor determina que en el marco de la UE, donde se cultiva anualmente una media de 2,7 millones de hectáreas de frutas y hortalizas, España ocupe el segundo lugar como productor (32\%) y que junto con Italia (36\%) aporten más de los dos tercios de la producción comunitaria (MAPA, 2004).

Cuadro 1. Principales zONAS de PRODUCCIÓN hortofrutícola en España

\begin{tabular}{|c|c|c|c|c|c|c|c|c|}
\hline \multirow[t]{2}{*}{ CCAA } & \multicolumn{2}{|c|}{ Total } & \multicolumn{2}{|c|}{ Hortalizas } & \multicolumn{2}{|c|}{ Frutales } & \multicolumn{2}{|c|}{ Cítricos } \\
\hline & $\begin{array}{c}\text { Miles } \\
\text { ha }\end{array}$ & $\begin{array}{c}\text { Miles } \\
\text { Tm }\end{array}$ & $\begin{array}{c}\text { Miles } \\
\text { ha }\end{array}$ & $\begin{array}{c}\text { Miles } \\
\text { Tm }\end{array}$ & $\begin{array}{c}\text { Miles } \\
\text { ha }\end{array}$ & $\begin{array}{c}\text { Miles } \\
\text { Tm }\end{array}$ & $\begin{array}{c}\text { Miles } \\
\text { ha }\end{array}$ & $\begin{array}{c}\text { Miles } \\
\text { Tm }\end{array}$ \\
\hline Andalucía & 421,3 & $6.942,2$ & 124,7 & $5.104,1$ & 228,5 & 418,3 & 68,1 & $1.419,8$ \\
\hline Cataluña & 161 & $1.611,5$ & 17,0 & 407,8 & 133,5 & $1.057,7$ & 10,5 & 146,0 \\
\hline C. Valenciana & 358,9 & $5.043,3$ & 27,4 & 901,5 & 147,1 & 303,3 & 184,4 & $3.838,5$ \\
\hline Región Murcia & 194,9 & $3.067,2$ & 49,2 & $1.701,7$ & 106,8 & 517,2 & 38,9 & 848,3 \\
\hline Total & $1.136,1$ & $16.664,2$ & 218,3 & $8.115,1$ & 615,9 & $2.296,5$ & 301,9 & $6.252,6$ \\
\hline \% España & 68,36 & 69,92 & 55,01 & 61,50 & 64,26 & 52,87 & 98,43 & 99,31 \\
\hline Total España & $1.661,9$ & $23.832,9$ & 396,8 & $13.194,0$ & 958,4 & $4.343,1$ & 306,7 & $6.295,8$ \\
\hline
\end{tabular}

Fuente: Hechos y cifras de la agricultura, la pesca y la alimentación en España (2006), MAPA.

A nivel nacional, el primer aspecto a destacar en la estructura productiva de este sector es su alta concentración espacial de forma que el litoral mediterráneo aporta casi el $70 \%$ de la superficie y la producción hortofrutícola española, siendo la Comunidad Andaluza la que se sitúa en primer lugar, aportando la cuarta parte de la superficie y el 30\% de la producción (cuadro 1). En esta región la concentración de las producciones es aún más intensa y pone de manifiesto la aportación tan importante que realiza el cordón litoral oriental, concretamente las provincias de Málaga, Granada y Almería donde se localiza el $70,2 \%$ de la superficie hortofrutícola andaluza y el $62 \%$ de la producción, ello supone el $17 \%$ de la superficie española y algo más del $15 \%$ de la producción. Desde el punto de vista económico la importancia no es menor, el sector frutas y hortalizas aporta el 35,2\% de la producción final agraria andaluza, contribuyendo las provincias orientales con algo más del $40 \%$.

El sudeste andaluz es, por tanto, la principal zona de cultivo hortofrutícola española y andaluza. En la actualidad se cultiva casi 300.000 ha de frutas y hortalizas, de ellas el $45,3 \%$ se sitúa en la provincia almeriense, el $36 \%$ en la provincia granadina y el $18,6 \%$ restante en la de Málaga. 
Por grupos de producto, el principal aporte superficial lo realizan los frutales no cítricos $(63,4 \%)$ debido a la importancia que adquieren los frutos secos, seguidos por las hortalizas $(26,2 \%)$ y los cítricos $(8,6 \%)$. En el lado de las producciones destacan las hortalizas, al aportar el $81,5 \%$ de la producción hortofrutícola, seguidas por los cítricos $(11,7 \%)$ y los frutales no cítricos (2,5\%) (cuadro 2a).

CUADRO 2A. SUPERFICIE y PRODUCCIÓN HORTOFRUtícola en El SUdESTE ANDALUZ (2005)

Cultivos Almería Granada Málaga Total \% Andalucía \% España

\begin{tabular}{lrrrrrr}
\hline SUPERFICIE (HA) & & & & & & \\
F. Cítricas & 12.163 & 683 & 12.549 & 25.395 & 38,60 & 8,30 \\
F. no cítricos & 71.811 & 84.118 & 29.177 & 185.106 & 87,64 & 19,05 \\
Hortalizas & 48.001 & 18.463 & 10.790 & 77.254 & 64,08 & 19,92 \\
Total & 131.975 & 103.264 & 52.516 & 287.755 & 72,38 & 17,28 \\
\hline PRODUCCIÓN (TM) & & & & & & \\
F. Cítricas & 232.155 & 18.414 & 241.400 & 491.969 & 39,35 & 19,91 \\
F. no cítricos & 18.798 & 96.578 & 64.270 & 179.646 & 51,45 & 7,61 \\
Hortalizas & 2.578 .448 & 570.997 & 270.009 & 3.419 .454 & 67,88 & 38,95 \\
Total & 2.829 .401 & 685.989 & 575.679 & 4.091 .069 & 61,65 & 17,19
\end{tabular}

Fuente: Anuario Estadístico de Andalucía (2006). IEA. Hechos y cifras de la agricultura, la pesca y la alimentación en España (2006), MAPA.

CUADRO 2B. SUPERFICIE y PRODUCCIÓN HORTOFRUTíCOLA EN EL SUDESTE ANDALUZ (1986)

Cultivos Almería Granada Málaga Total \% Andalucía \% España

\begin{tabular}{lrrrrrr}
\hline SUERFICIE (HA) & & & & & & \\
F. cítricas & 6.248 & 1.214 & 11.220 & 18.682 & 46,5 & 7,33 \\
F. no cítricos & 56.064 & 58.215 & 30.134 & 144.413 & 84,07 & 16,37 \\
Hortalizas & 30.102 & 13.361 & 14.300 & 57.763 & 52,00 & 12,12 \\
Total & 92.414 & 72.790 & 55.654 & 220.858 & 68,36 & 13,69 \\
\hline PRODUCCIÓN (TM) & & & & & & \\
F. cítricas & 65.404 & 12.320 & 128.917 & 206.641 & 44,17 & 12,10 \\
F. no cítricos & 41.326 & 77.460 & 44.604 & 163.390 & 60,7 & 5,34 \\
Hortalizas & 1.190 .766 & 426.531 & 434.537 & 2.051 .834 & 65,09 & 6,18 \\
Total & 1.297 .496 & 516.311 & 608.058 & 2.421 .865 & 62,27 & 14,97 \\
\hline
\end{tabular}

Fuente: Anuario Estadístico Agraria (1986), MAPA.

Un aspecto a destacar en este espacio es la especialización productiva de cada provincia en torno a un subsector hortofrutícola. Almería se especializa en hortalizas con el $62,1 \%$ de la superficie y las tres cuartas partes de la producción del sudeste andaluz concentradas en las comarcas costeras (Campo de Dalías, Campo de Níjar-Bajo Andarax y Bajo Almanzora); el 
resto de la superficie hortícola se la reparten Granada (23,8\%) y Málaga $(13,9 \%)$, también con una localización claramente litoral en sus producciones intensivas (comarca de La Costa en Granada y de Vélez-Málaga en Málaga). La superficie de los cítricos se reparte equitativamente entre las provincias de Málaga (49\%) y Almería (47,8\%), prioritariamente en las comarcas del Guadalhorce y Bajo Almanzora, respectivamente. En frutales, si atendemos únicamente a los regados, Málaga y Granada son las principales zonas de cultivo debido a la presencia de los frutales subtropicales en sus comarcas litorales.

Con respecto a 1986, lo destacable es el crecimiento del sector en algo más de 61.000 ha (si no se contabilizan los frutos secos el crecimiento se sitúa en 28.000 ha) y en 1,6 millones de Tm (cuadros 2 a y 2 b), habiendo participado en dicho incremento los tres grupos de productos que integran el conjunto hortofrutícola: cítricos y hortalizas han aumentado cada uno un tercio su superficie, los frutales un $28,1 \%$.

Como es sabido, el sector hortofrutícola está conformado por una gran diversidad y variedad de especies. En el cuadro 3 se recogen los 13 productos en que más destaca el sudeste andaluz, los cuales representan el $88,9 \%$ de las superficie hortofrutícola del litoral y el $87,6 \%$ de la producción, además en esta zona se encuentran las dos terceras partes de la superficie y producción andaluza en estos cultivos.

Cuadro 3. Principales Cultivos hortofrutícolas en el SuDESTE andaluz

\begin{tabular}{lrrrr} 
Cultivos & \multicolumn{5}{c}{2005} \\
& Ha & \% Andalucía & Tm & $\%$ Andalucía \\
\hline Lechuga & 10.341 & 87,11 & 237.802 & 81,97 \\
Melón & 6.000 & 66,55 & 212.100 & 75,66 \\
Sandía & 5.640 & 66,19 & 359.460 & 77,34 \\
Calabacín & 4.440 & 91,92 & 182.409 & 92,33 \\
Pepino & 5.720 & 94,18 & 401.325 & 99,54 \\
Tomate & 13.550 & 62,68 & 965.432 & 64,42 \\
Pimiento & 10.455 & 81,26 & 581.435 & 88,19 \\
J. verdes & 7.000 & 91,68 & 89.905 & 92,93 \\
Naranjo & 13.912 & 30,44 & 257.744 & 33,15 \\
Limón & 7.877 & 93,57 & 166.212 & 99,04 \\
Chirimoyo & 3.207 & 98,43 & 27.024 & 99,63 \\
Aguacate & 8.645 & 96,77 & 75.098 & 100 \\
Almendro & 163.012 & 94,59 & 4.515 & 65,34 \\
& & & &
\end{tabular}

Fuente: Anuario de Estadística Agraria (1986), MAPA.

Anuario Estadístico de Andalucía (2006), IEA. 
Por último, hay que señalar que la importancia de la superficie hortícola se incrementa si consideramos que existen dos ciclos de cultivos, el de otoño-invierno y el de primavera-verano. Respecto a las combinaciones de cultivos se advierte una pequeña diferenciación entre el litoral almeriense y el resto del litoral. En Almería casi la mitad de la superficie se cultiva en monocultivo, siendo el producto más importante el tomate, seguido de la alternativa pimiento/melón y pimiento/sandía, el resto de alternativas es mucho más variada y se trata más frecuentemente de monocultivo (Junta de Andalucía, 2002). En el resto de la costa, las alternativas más frecuentes son las asociaciones judías de otoño/tomate de primavera, tomate de otoño/patata de temporada y patata de otoño/melón/sandía (poco frecuente).

\section{RENTABILIDAD, COSTES DE PRODUCCIÓN Y MARGEN DE BENEFICIOS DE LAS EXPLOTACIONES HORTOFRUTÍCOLAS}

El beneficio de cualquier empresa viene determinado por la relación entre ingresos y gastos. La evolución divergente que estas variables han experimentado, en las últimas campañas, en las explotaciones hortofrutícolas del sudeste andaluz, induce a analizar la situación. En primer lugar atenderemos a los parámetros que componen los ingresos (precios de venta, rendimientos y producción) y, en segundo lugar, los gastos en los que incurren las explotaciones.

En la figura 2 ( $a$, b y c) aparecen recogidos la evolución de los principales parámetros que conforman la rentabilidad de las explotaciones. Como punto de partida se puede apuntar que el señalado crecimiento de la producción hortofrutícola (1,6 millones de Tm desde 1986) se ha debido fundamentalmente al aumento de los rendimientos de los cultivos ( $\mathrm{Tm} / \mathrm{ha}$ ), ya que mientras la superficie de cultivo ha crecido un $30 \%$, la producción lo ha hecho en un $68,9 \%$, debido a la mejora de estructuras, introducción de nuevas variedades, mejoras en el control climático de invernaderos, etc. Por grupos de productos, las hortalizas han duplicado los rendimientos, los subtropicales los han incrementado un $25 \%$ y los cítricos un $6 \%$.

Los rendimientos crecientes se han mantenido hasta finales de la década de los noventa, cuando se aprecia un cierto declive. En hortalizas esta tendencia ha estado motivada, en parte, por el uso de nuevas variedades resistentes o tolerantes a determinadas plagas y enfermedades, pero menos 
productivas y a la masiva incorporación de mallas en las ventanas de los invernaderos como métodos de lucha contra plagas y enfermedades, que al reducir la aireación de los mismos empeoran las condiciones ambientales afectando a su productividad (Junta de Andalucía, 2002). En el caso de los frutales se ha debido a las reiteradas sequías y a la vecería propia de estos cultivos.

FIGURA 2. EVOLUCIÓN DE LA RENTABILIDAD DE LA PRODUCCIÓN HORTOFRUTÍCOLA DEL SUDESTE ANDALUZ (1986-2006)
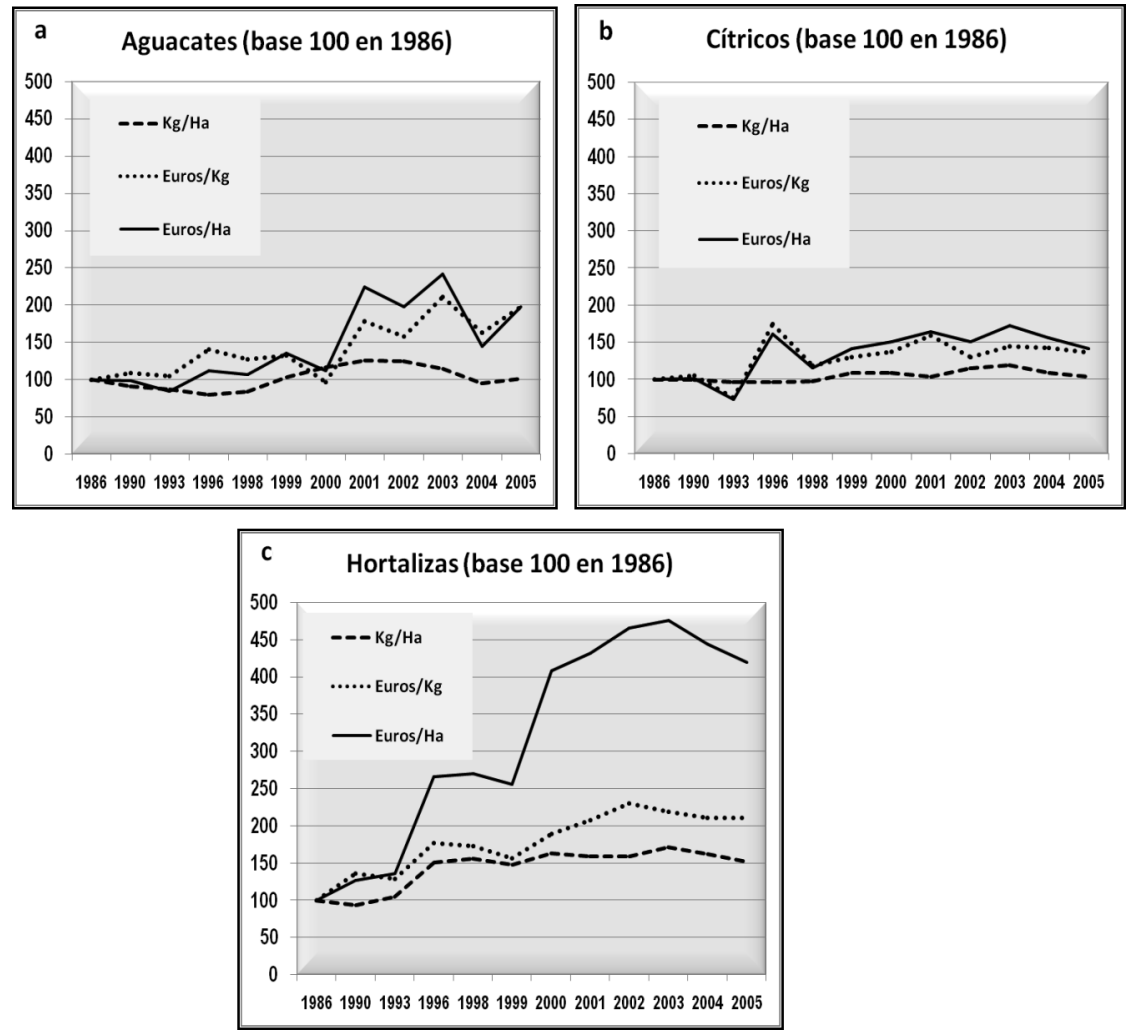

Fuente: Anuarios de Estadística Agroalimentaria, MAPA.

Observando los hechos recogidos en la figura 2 destacaríamos que la consecuencia inmediata de la estabilización de los rendimientos y la ligera disminución de los precios medios han supuesto un retroceso de la rentabilidad de las explotaciones que mantuvieron su dinamismo mientras que los incrementos de producción compensaban los altibajos de los precios. Por 
grupo de productos, se observa que han sido cítricos y hortalizas, donde la caída de los precios siempre había sido compensada con aumentos en la productividad, los más afectados en la actualidad por la devaluación de la renta al no ser compensada la caída de los precios con crecimientos productivos (figuras $2 \mathrm{~b}$ y $2 \mathrm{c}$ ). Los frutales subtropicales, en cambio, mantienen actualmente la rentabilidad de las explotaciones al haber estado ésta más ligada al aumento de los precios que al de los rendimientos de los cultivos (figura 2a).

La segunda variable de la que depende el beneficio de las empresas es, los gastos de explotación que han presentado un importante crecimiento a lo largo de la presente década, de forma que se suman a este haz de factores que están restando margen de beneficio a las explotaciones.

Para evaluar los costes de producción hortofrutícola hemos elegido una explotación tipo de hortalizas, por ser el sector que más está acusando en las últimas campañas la pérdida de beneficios. Considerando las orientaciones productivas más frecuentes en la zona y aportando a la explotación los factores de producción necesarios, se observa que desde finales de la década de los noventa se ha producido un incremento de los gastos de explotación del 13,3\% (5.200 €/ha), donde los dos componentes que lo integran (gastos corrientes y de amortización) han aumentado respectivamente en un 10,3 y un $13,3 \%$ (cuadro 4 ).

CuAdro 4. EVOLUCIÓN DE LOS COSTES DE PRODUCCIÓN HORTOFRUTíCOLA

\begin{tabular}{|c|c|c|c|c|c|c|c|c|}
\hline \multirow[t]{2}{*}{ Conceptos } & \multicolumn{2}{|c|}{$\begin{array}{c}\text { Campaña 1999- } \\
2000\end{array}$} & \multicolumn{2}{|c|}{$\begin{array}{c}\text { Campaña 2000- } \\
2001\end{array}$} & \multicolumn{2}{|c|}{$\begin{array}{c}\text { Campaña 2003- } \\
2004\end{array}$} & \multicolumn{2}{|c|}{$\begin{array}{c}\text { Campaña 2004- } \\
2005\end{array}$} \\
\hline & $\begin{array}{l}\text { Gasto } \\
(€ / \text { ha })\end{array}$ & $\begin{array}{c}\% \\
\text { gastos }\end{array}$ & $\begin{array}{l}\text { Gasto } \\
(€ / \text { ha })\end{array}$ & $\begin{array}{c}\% \\
\text { gastos }\end{array}$ & $\begin{array}{l}\text { Gasto } \\
(€ / \text { ha })\end{array}$ & $\begin{array}{c}\% \\
\text { gastos }\end{array}$ & $\begin{array}{l}\text { Gasto } \\
(€ / \text { ha })\end{array}$ & $\begin{array}{c}\% \\
\text { gastos }\end{array}$ \\
\hline GASTOS & & & & & & & & \\
\hline $\begin{array}{l}\text { CORRIENTES } \\
\text { Mano de obra } \\
\text { Semillas }\end{array}$ & $15.265,7$ & 32,1 & $16.032,0$ & 32,6 & 18.550 & 36,2 & 19.106 & 36,2 \\
\hline y plantones & $4.534,6$ & 9,5 & $4.761,2$ & 9,7 & 3.687 & 7,2 & 3.908 & 7,4 \\
\hline Agua & $1.114,9$ & 2,3 & $1.137,2$ & 2,3 & 1.250 & 2,4 & 1.250 & 2,4 \\
\hline Agroquímicos & $7.440,5$ & 15,6 & $7.539,7$ & 15,4 & 7.986 & 15,6 & 8.028 & 15,2 \\
\hline Energía & 841,4 & 1,8 & 976,0 & 2,0 & 954 & 1,9 & 983 & 1,9 \\
\hline Servicios & $5.649,5$ & 11,9 & 5.706 & 11,6 & 4.986 & 9,7 & 5.098 & 9,7 \\
\hline Otros gastos & $1.253,1$ & 2,6 & $1.292,2$ & 2,6 & 1.416 & 2,8 & 1.458 & 2,8 \\
\hline Total & $36.099,8$ & 75,9 & $37.444,3$ & 76,2 & 38.811 & 75,8 & 39.831 & 75,4 \\
\hline
\end{tabular}


Cuadro 4. Evolución de los costes de PROducción hORTOFrutícola (CONT.)

\begin{tabular}{|c|c|c|c|c|c|c|c|c|}
\hline \multirow[t]{2}{*}{ Conceptos } & \multicolumn{2}{|c|}{$\begin{array}{c}\text { Campaña 1999- } \\
2000\end{array}$} & \multicolumn{2}{|c|}{$\begin{array}{c}\text { Campaña 2000- } \\
2001\end{array}$} & \multicolumn{2}{|c|}{$\begin{array}{c}\text { Campaña 2003- } \\
2004\end{array}$} & \multicolumn{2}{|c|}{$\begin{array}{c}\text { Campaña 2004- } \\
2005\end{array}$} \\
\hline & $\begin{array}{l}\text { Gasto } \\
(€ / \text { ha })\end{array}$ & $\begin{array}{c}\% \\
\text { gastos }\end{array}$ & $\begin{array}{l}\text { Gasto } \\
(€ / \text { ha })\end{array}$ & $\begin{array}{c}\% \\
\text { gastos }\end{array}$ & $\begin{array}{l}\text { Gasto } \\
(€ / \text { ha })\end{array}$ & $\begin{array}{c}\% \\
\text { gastos }\end{array}$ & $\begin{array}{l}\text { Gasto } \\
(€ / \text { ha })\end{array}$ & $\begin{array}{c}\% \\
\text { gastos }\end{array}$ \\
\hline $\begin{array}{l}\text { GASTOS DE } \\
\text { AMORTIZACIÓN }\end{array}$ & & & & & & & & \\
\hline $\begin{array}{l}\text { Sustrato } \\
\text { Estructura }\end{array}$ & $2.001,5$ & 4,2 & $2.103,5$ & 4,3 & 2.350 & 4,6 & 2.445 & 4,6 \\
\hline invernadero & $3.906,6$ & 8,2 & $3.906,6$ & 8,0 & 4.000 & 7,8 & 4.000 & 7,6 \\
\hline Plásticos & $1.803,0$ & 3,8 & $1.893,2$ & 3,9 & 2.300 & 4,5 & 2.723 & 5,2 \\
\hline Sistema de riego & $2.253,8$ & 4,7 & $2.253,8$ & 4,6 & 2.180 & 4,3 & 2.220 & 4,2 \\
\hline Balsas de riego & 390,7 & 0,8 & 390,7 & 0,8 & 345 & 0,7 & 345 & 0,7 \\
\hline Otros & $1.099,9$ & 2,3 & $1.117,9$ & 2,3 & 1.220 & 2,4 & 1.250 & 2,4 \\
\hline Total & $11.455,3$ & 24,1 & $11.665,6$ & 23,8 & 12.395 & 24,2 & 12.983 & 24,6 \\
\hline $\begin{array}{l}\text { Total gastos } \\
\text { anuales }\end{array}$ & $47.555,1$ & 100,0 & $49.110,0$ & 100,0 & 51.206 & 100,0 & 52.814 & 100,0 \\
\hline
\end{tabular}

Fuente: Instituto de Estudios de Caja Rural de Almería (2001-2006), Anuario de la Agricultura Almeriense.

El concepto que más peso tiene en los gastos corrientes es la mano de obra que representa más de un tercio de los gastos de explotación, con una tendencia al alza en los últimos tiempos debido a la progresiva sustitución de la mano de obra familiar por asalariada. Se puede decir que este concepto ha sido el principal responsable del incremento de los costes de producción. Otro concepto que siempre ha tenido un peso elevado en los costos de producción ha sido los agroquímicos, si bien su costo se ha estabilizado en este periodo, aunque su uso es muy dependiente de las circunstancias por las que transcurran anualmente las campañas en relación a plagas y enfermedades. En las restantes partidas se ha observado una disminución del gasto (semillas, plantones, energía y servicios).

En el capítulo de los gastos de amortización han sido los plásticos los responsables fundamentales del incremento de los gastos $(1,4 \%)$ por el crecimiento de los precios del petróleo; las restantes partidas bien se estabilizan o presentan pequeños incrementos.

En este punto podemos decir que los gastos corrientes medios en este periodo para una unidad de producción tipo se sitúan en torno a los $3,8 € / \mathrm{m}^{2}$, a esta cantidad habría que sumarle los costes de amortización que se han estimado en $1,2 € / \mathrm{m}^{2}$, con lo que se obtendría un coste de producción de $5,0 € / \mathrm{m}^{2}$ (50.000 €/ha), esto supone que el límite de precio del producto en origen, sólo para cubrir costos, se debe situar en $0,50 € /$ ha. 
Considerando los gastos de cultivos, los rendimientos medios y los precios medios al principio y al final del periodo analizado, se aprecia que la rentabilidad del sector hortícola se ha devaluado. En la campaña 1999-2000, con una producción media de $90.000 \mathrm{~kg} / \mathrm{ha}$, vendido el producto a un precio medio de $0,58 € / \mathrm{kg}$, se obtuvo un margen de beneficio medio por explotación de $4.644,9 €$ frente a los $1.186 €$ de la campaña 2004-2005 propiciado por el incremento de costos (11\%), estabilización de rendimientos y de precios medios anuales $(0,60 € / \mathrm{ha})$.

En un análisis individualizado de los principales cultivos que integran la producción hortofrutícola se concluye que el margen de beneficio de la mayoría de los productos se ha ido estrechado, puesto que la diferencia entre el costo de producción y el precio de venta de un kilogramo de producto se ha reducido, dejando un margen de fluctuación muy estrecho a precios y a rendimientos. En hortalizas, el cultivo con mayor costo de producción es el tomate, seguido de pimientos y berenjenas, costes de cultivos que obligan a obtener precios en origen superiores a $0,46 € /$ ha para los primeros, 0,63 para los segundos y 0,57 para la berenjena. Los cultivos más rentables son el pimiento y el tomate, al ser compensados los elevados costes de producción con los rendimientos por hectáreas y los precios de venta, ello demuestra que los costes de cultivo no presentan una relación directa con el precio final del producto. Los hortícolas con menor margen neto son judías verdes y sandías, las primeras debido a que los bajos rendimientos por hectáreas no se ven compensados por las elevadas cotizaciones, la mayor del conjunto hortícola, y los segundos por tener una de las cotizaciones más bajas del conjunto hortícola. En el capítulo de los frutales los aguacates son uno de los productos con mayor margen entre precios de producción y de venta, con lo que la viabilidad futura de las explotaciones, aún con estabilización de precios y subida de costes, está asegurada, a diferencia de los limones, donde no cabe más reducción de márgenes. Respecto a la campaña 1999-2000, el retroceso de los beneficios es un hecho en todos los productos, al incrementarse los costos de producción de kilogramos de producto, siendo los incrementos más acusados los de judías verdes $(0,39 € / \mathrm{kg})$ y pimientos $(0,31 € € / \mathrm{kg})$ (cuadro 5).

\section{EL DESTINO COMERCIAL DE LAS PRODUCCIONES HORTOFRUTÍCOLAS}

Analizar el destino de la producción hortofrutícola es importante por dos motivos, porque la proyección exterior de la producción es un elemento distintivo de los distritos de producción industrial y porque los mercados de destino imponen las pautas de actuación en los de origen. 
CuAdro 5. MARGEN DE PRODUCCIÓN DE lOS PRINCIPALES CULTIVOS HORTOFRUTíCOLAS

\begin{tabular}{|c|c|c|c|c|c|c|c|c|c|}
\hline \multirow[t]{2}{*}{ Cultivos } & \multicolumn{2}{|c|}{ Gastos corrientes } & \multirow[t]{2}{*}{$\begin{array}{c}\text { Gastos } \\
\text { amortización }\end{array}$} & \multirow[t]{2}{*}{$\begin{array}{l}\text { Total } \\
\text { gastos }\end{array}$} & \multirow[t]{2}{*}{$\begin{array}{l}\text { Producción } \\
\text { media }\end{array}$} & \multicolumn{2}{|c|}{$\begin{array}{c}\text { Precio } \\
\text { producción } \\
(€ / \mathrm{kg})\end{array}$} & \multirow{2}{*}{$\begin{array}{l}\text { Precio } \\
\text { en } \\
\text { origen } \\
(€ / \mathrm{kg})\end{array}$} & \multirow{2}{*}{$\begin{array}{c}\text { Margen } \\
\text { neto } \\
\text { actual } \\
(€ / \text { ha })\end{array}$} \\
\hline & $\begin{array}{l}\text { Mano } \\
\text { de obra }\end{array}$ & $\begin{array}{l}\text { Otros } \\
\text { gastos }\end{array}$ & & & & $\begin{array}{l}2004- \\
2005\end{array}$ & $\begin{array}{l}1999- \\
2000\end{array}$ & & \\
\hline Sandía & $5.941,26$ & $7.710,53$ & $3.250,11$ & $16.901,9$ & 65.000 & 0,27 & 0,23 & 0,31 & $3.248,1$ \\
\hline Melón & $7.921,68$ & $7.715,29$ & $4.718,41$ & $20.355,38$ & 45.000 & 0,49 & 0,38 & 0,58 & $5.744,6$ \\
\hline Tomate & $20.794,41$ & $10.433,24$ & $\begin{array}{l}1.1178,55 \\
\end{array}$ & $42.406,20$ & 91.000 & 0,46 & 0,31 & 0,55 & $7.643,8$ \\
\hline Pimiento & $13.862,94$ & $15.189,45$ & $7.555,493$ & $36.557,88$ & 58.000 & 0,63 & 0,32 & 0,85 & $12.742,1$ \\
\hline Pepino & $9.902,10$ & $7.299,88$ & $5.454,95$ & $27.894,77$ & 86.000 & 0,32 & 0,22 & 0,39 & $5.645,2$ \\
\hline Calabacín & $9.902,10$ & $7.299,88$ & $\begin{array}{l}3.638,39 \\
\end{array}$ & $22.840,37$ & 62.000 & 0,36 & 0,27 & 0,48 & $6.919,6$ \\
\hline Berenjena & $15.843,36$ & $10.702,14$ & $8.675,8$ & $3.5221,3$ & 61.000 & 0,57 & 0,39 & 0,67 & $5.647,7$ \\
\hline J. verde & $11.882,52$ & $8.681,72$ & $3.422,812$ & $23.987,05$ & 18.000 & 1,31 & 0,91 & 1,60 & $4.812,9$ \\
\hline Limón & $1.171,97$ & 682,98 & 350,0 & $2.204,95$ & 22.000 & 0,10 & 0,5 & 0,18 & $1.758,0$ \\
\hline Aguacate & $2.653,64$ & $1.362,58$ & 601,01 & $4.228,23$ & 9.000 & 0,47 & 0,36 & 1,15 & $6.121,7$ \\
\hline
\end{tabular}

Fuente: Palao y Salinas (2007), CAPJA, Encuestas a agricultores.

En el destino de la producción hortofrutícola del sudeste andaluz el consumo en fresco y la exportación tienen más peso que en el español, por el contrario el peso de la industrialización es menor (figuras 3 y 4). De las 4,1 millones de Tm producidas en el litoral andaluz, el 98,7\% (4,02 millones de Tm) es producción comercializable (el 94,7\% en el caso español), el resto son las cantidades que no transcurren por los circuitos normales de comercialización (pérdidas, retiradas de producto, etc.). Dentro de la producción comercializable se impone el consumo en fresco, el 90,7\% de la producción (un 16,5\% más que en España), frente a la industrialización, el 7,5\% (un 13,1\% menos que en el conjunto español). El poco peso de esta última vía se debe a la calidad de las producciones del sudeste andaluz, a los mayores niveles de precios conseguidos en fresco y a las escasas ayudas para la transformación (Larrubia, 1991). De la producción en fresco el 57,1\% se exporta frente al $37,3 \%$ de la española, debido a las mayores cotizaciones que se consiguen en el mercado internacional frente al nacional, donde la poca valoración de la relación calidad-precio por parte del consumidor no aconseja este mercado, a donde siempre se ha dirigido las segundas calidades (Larrubia, 1995).

La exportación hortofrutícola constituye, pues, el principal destino de la producción hortofrutícola del sudeste andaluz. Su importancia se debe no sólo al volumen de producto que transcurre por esta vía (60\% de hortalizas y cítricos, 51,4\% los frutales subtropicales), a su evolución continuada desde 1986 con crecimiento del $11 \%$, sino también a la aportación que este espacio realiza al conjunto de la exportación hortofrutícola española (37\%) (cuadro 6). 
Figura 3. Destino de la producción hortofrutícola (España)

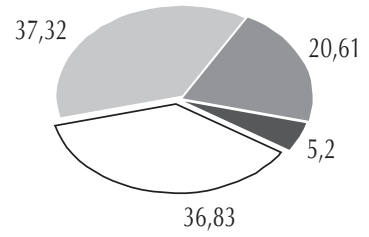

Mercado interior

Mercado exterior

Transformación

Pérdidas y retiradas
2005

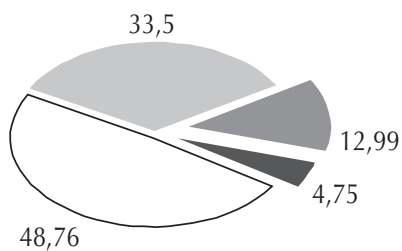

Mercado interior

Mercado exterior

Transformación

Pérdidas y retiradas

1986

Figura 4. Destino de La producción hORTOfRUtícola (sudeste andaluz)

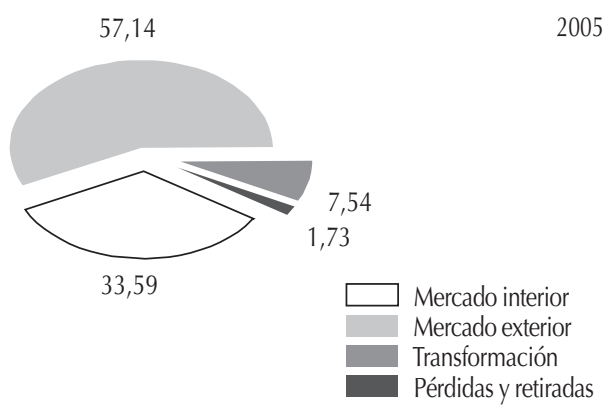

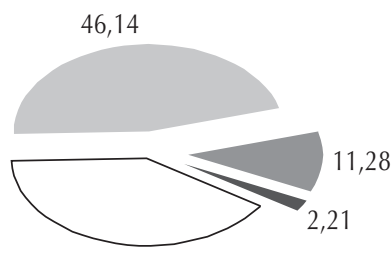

40,37

Cuadro 6. Principales espeCies exportadas deSDE el sudeste ANDAluZ

Hortalizas

Col
Lechuga
Sandía
Melón
Pepino
Calabacín
Berenjena
Tomate
Pimiento
Judías verdes
Otras hortalizas
Chirimoyos
Aguacates
Cítricos
Total

$\%(1)$

23

10,09

56,19

32,7

70,18

82,60

78,8

28,61

63,7

65,7

5,66

100

90

60

33
$\%$ (2)

90,3
30,3
40,17
43,08
89,1
49,63
63,6
38,24
60,4
20,04
23,17
6,4
51,4
8,41
57,14

30,3

40,17

4,08

63,6

38,24

60,4

20,04

3,17

51,4

57,14

(1) Aportación del Litoral Oriental Andaluz en la corriente exportadora española de cada especie.

(2) Volumen exportado respecto al producido desde el LOA.

Fuente: SOIVRE y MAPA. 
Un aspecto a destacar en la corriente de exportación hortofrutícola del sudeste andaluz, al igual que en el caso español, es el elevado grado de concentración geográfica, puesto que el principal mercado de destino ha sido el comunitario, al que se dirige algo más del 90\% de la producción, con un incremento importante desde la integración española, de forma que ha pasado de recibir 3,5 millones de Tm a más de 9 millones de Tm. Dicha concentración geográfica se acentúa si consideramos que unos cuantos destinos se reparten el grueso de la producción; así los mercados de Alemania y Francia reciben el $70 \%$ de la exportación, seguidos de los mercados británicos y holandés con el $12,6 \%$, en el $18 \%$ restante participan un importante abanico de países, entre los que destacan Italia, Suecia, Bélgica y Luxemburgo dentro de los países de Europa Occidental, y la República Checa y Polonia entre los países del Este de Europa. Fuera del ámbito europeo sólo cabe mencionar insignificantes y esporádicos envíos a EE UU y Canadá (figura 5a).

Figura 5. EXPORTACIÓN HORTOFRUTíCOLA: A) POR MERCADOS DE DESTINO; B) POR MESES
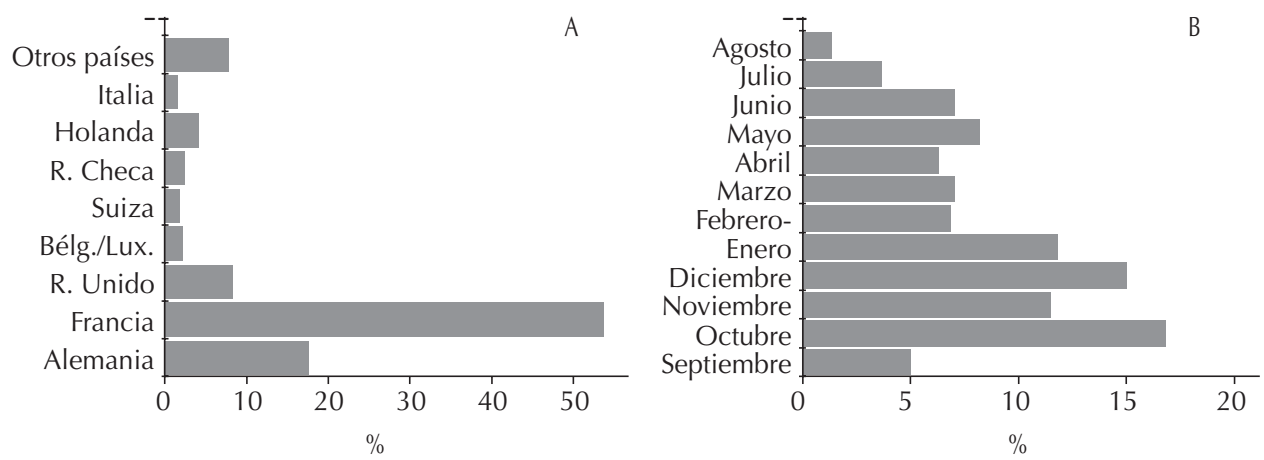

Fuente: SOIVRE.

El segundo aspecto a destacar es que la corriente de exportación se mantiene prácticamente todo el año, debido a la sucesión de las distintas especies y variedades, con dos momentos claves, la campaña de otoño-invierno (octubre-enero) que da salida al 54,5\% de la exportación, y la de primavera-verano (abril-junio) con el 28,5\% de la producción (figura $5 b)$.

El análisis de la exportación de los tres grupos de productos que integran la producción hortofrutícola del sudeste andaluz permite establecer algunas diferenciaciones respecto al esquema general comentado. 
Considerando el destino de las producciones, en los tres grupos se aprecia un elevado grado de concentración espacial y la preeminencia de los envíos a la UE, aunque es el grupo de subtropicales, donde el aguacate constituye la especie reina de la exportación, el que presenta la máxima concentración geográfica al dirigir a Francia el 93,8\% de lo exportado, no en vano éste es el primer importador mundial de aguacates (figura 6).

FIGURA 6. EXPORTACIONES DE AGUACATES POR MERCADOS DE DESTINO

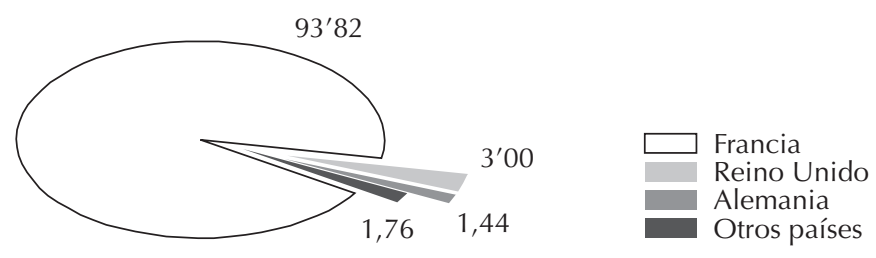

Fuente: SOIVRE.

En cítricos dos países, Francia y Reino Unido, acaparan las tres cuartas partes de lo exportado (figura 7a), mientras que los envíos de hortalizas poseen una mayor diversificación geográfica, distribuyéndose algo más de las tres cuartas partes entre cuatro países (Alemania, Francia, Holanda y el Reino Unido) (figura 7b).

FIGURA 7. EXPORTACIÓN POR MERCADOS DE DESTINO: A) DE CítRICOS; B) DE HORTALIZAS
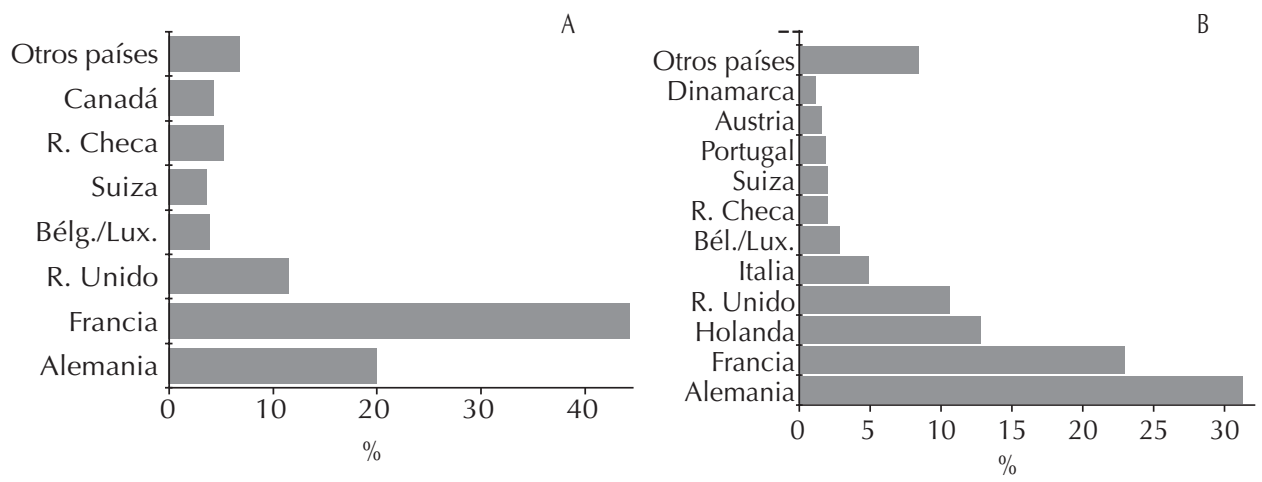

Fuente: SOIVRE. 
En cuanto al calendario de exportación, son hortalizas y cítricos las especies que presentan menor concentración temporal puesto que, a excepción de los meses veraniegos, mantienen en casi toda la campaña un considerable volumen de exportación. En la campaña de exportación de hortalizas se puede distinguir tres periodos fuertes: el de octubre a febrero (48,5\% de la exportación anual) que constituye la campaña de exportación de invierno, siendo las principales especies exportadas las que se obtienen bajo protección; el de marzo-abril, donde se produce un descenso en el volumen exportado $(17,37 \%)$, y constituye la campaña de final de invierno y primavera, en ella se producen las máximas salidas de tomates, judías verdes, coles, el segundo incremento de pepinos y calabacines y se inician las salidas de las especies veraniegas y el de mayo-junio (25\%) que constituye la campaña de primavera-verano, donde melones y sandías son las principales especies exportadas (figura 8a).

En cítricos la sucesión del periodo de producción de las distintas especies determina que permanezcan casi todo el año en los mercados, con dos momentos claves: el mes de enero (casi el $20 \%$ ) y los meses de mayo-junio $(27 \%)$ (figura $8 b$ ).

Figura 8. EXPORTACIÓN MENSUAL: A) DE HORTALIZAS; B) DE CÍTRICOS
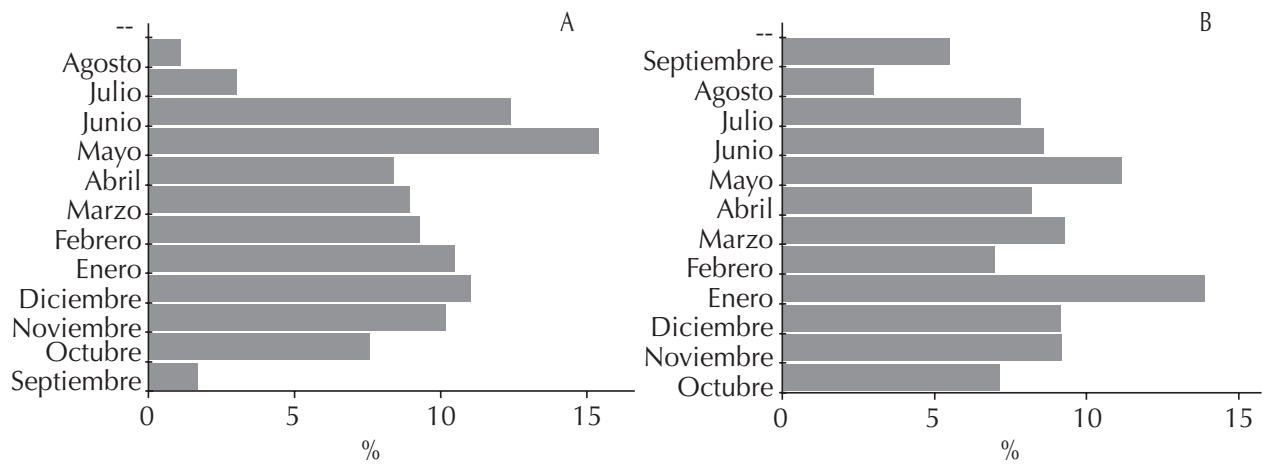

Fuente: SOIVRE.

Vuelve a ser la campaña de exportación de los aguacates la que presenta un mayor grado de concentración temporal, en tan sólo cinco meses (septiembre-enero) se da salida al 90\% de la producción, son casi nulos los envíos de junio-julio y muy importantes los de octubre y diciembre (figura 9), coincidiendo con las variedades Fuerte y Hass, siendo esta última la variedad reina de la exportación española. 
Figura 9. EXPORTACIÓN MENSUAL DE AGUACATES

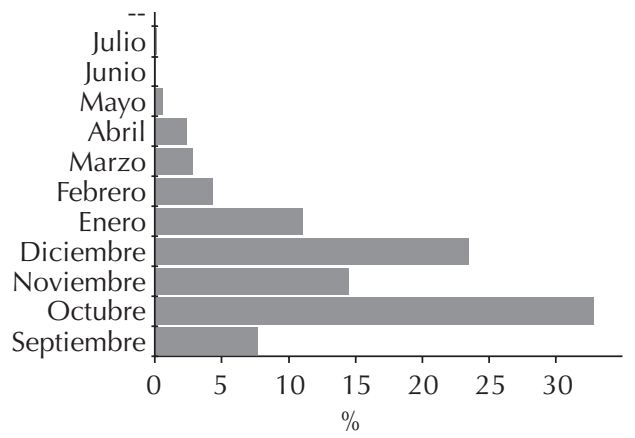

Fuente: SOIVRE.

\section{LA (NO) REGULACIÓN DEL MERCADO DE FRUTAS Y HORTALIZAS}

Las relaciones institucionales del sector hortofrutícola vienen marcadas, por un lado, por la pertenencia a la Unión Europea y lo que supone de acatar los diversos acuerdos bilaterales y multilaterales que ésta tiene suscrito y, por otro lado, por el nuevo marco de negociación de la Organización Mundial del Comercio que pretende profundizar en los procesos de liberación del comercio.

Respecto al marco comunitario hay que partir de la base de que el sector frutas y hortalizas nunca ha gozado de ventajas dentro de este marco regional, ni en relación a otras producciones, ni a otras zonas productoras. Las excelentes expectativas que tenía el sector ante la incorporación española a la entonces CEE pronto se desvanecieron debido a la dureza de las condiciones de adhesión que se gestaron en dos etapas. Durante la primera etapa de la adhesión el sector mantuvo una posición muy cercana a la que poseía cuando se le otorgaba a España la condición de "tercer país", aunque se inició la adecuación del sector a las estructuras comunitarias mediante la aplicación en el mercado interior del corpus legislativo comunitario (estricto cumplimiento de las normas de calidad, desarrollo de organización de productores, etc.), el establecimiento de los precios institucionales (precios de base, precios de compra y precios de retirada) para aquellos productos que contaban con ellos en la Comunidad y se inició el desarme arancelario que terminaría, en principio en 1996, aunque sus efectos no se dejarían ver, al menos, hasta el sexto año de la adhesión debido a que en muchos productos se partía con tarifas y gravámenes arancelarios 
superiores a los soportados por el resto de terceros países de la Cuenca del Mediterráneo, quienes, en base a acuerdos preferenciales, tenían reducidos su arancel aduanero. En el segundo periodo de la adhesión mejoró la posición del sector al adelantarse a enero de 1993 el desmantelamiento total del desarme arancelario. El aspecto más controvertido en esta fase fue la aplicación del denominado Mecanismo Complementario de los Intercambios $(\mathrm{MCl})$ que nunca había figurado en otras adhesiones y que tenía como objeto moderar las exportaciones de 10 productos hortofrutícolas considerados sensibles, adecuándolas a las necesidades del mercado importador (Larrubia, 1998).

La integración del sector hortofrutícola español en el marco comunitario supuso la organización del sector a través de la OCM (Organización Común de Mercado) para frutas y hortalizas. La OCM se había instaurado en 1972 (R. CEE $n^{\circ}$ 1035/72) y se había organizado en dos grupos de reglamentos: el primer grupo vigilaba el buen funcionamiento de los mercados interiores de los propios países comunitarios a través de diferentes medidas (normas de calidad, organizaciones de productores, régimen de precios de intervención, etc.), el segundo grupo incluía reglamentos que protegían las producciones comunitarias de las de terceros países (sistemas de contingencia, precios de referencias, tasas compensatorias, etc.). El nuevo reglamento que se establece en 1996 (R. CE n 2.200/96) mantiene, a grandes rasgos, el sistema de regulación previo y en función de los nuevos objetivos (mejorar la eficacia y calidad de las producciones, ajustar las producciones a la demanda y aplicar los compromisos del Gatt en el régimen de intercambios con terceros países) fija las siguientes aspiraciones:

- Potenciar las organizaciones de productores (OP).

- Sustituir el precio de retirada (precio que paga las OP a sus asociados por debajo del cual no sacan sus productos al mercado) por indemnizaciones comunitarias de retirada.

- Crear un fondo operativo cofinanciado por la UE e implementado por las organizaciones de productores, destinado a financiar acciones de mejora de la producción y comercialización.

La reforma posterior contenida en el R. (CE) 2699/00 modifica sólo algunos aspectos puntuales, manteniendo a grandes rasgos el sistema de regulación previo. La reforma afecta a los fondos operativos que incrementan su cuantía $(1,6 \%)$, a los umbrales de transformación de producciones 
para la industria y al importe de las ayudas (un aumento de los límites de producción para tomates, cítricos y peras y de sus ayudas respectivas) y, también, contempla la vigilancia de las concesiones y acuerdos con terceros países. La posterior reforma de 2003 (R. $n^{\circ} 1782$ ) no incluye cambios directos para la OCM de frutas y hortalizas, ni siquiera las comunicaciones de la Comisión para las producciones mediterráneas tratan de ellas.

En la actualidad el sector se encuentra pendiente de una nueva reforma cuyo objeto, según Bruselas, será aumentar la competitividad del sector y ponerlo en línea con las disposiciones de la Política Agraria Comunitaria que se aplica en otros sectores agrícolas. Se trataría de pasar de un apoyo a la producción a una ayuda directa a los productores, lo que contribuiría a promover una agricultura sostenible y más orientada al mercado. Ante tal reforma, el sector hortofrutícola no oculta su preocupación, pues continuamos con la reiterada discriminación histórica de la agricultura mediterránea en la PAC. La reforma se propone con un presupuesto neutral para un sector que aportando un $17 \%$ a la producción final agraria comunitaria, sólo percibe un 3,1\% del presupuesto del FEOGA-sección garantía. No ha sido nunca, ni parece que será, un sector consumidor de presupuesto, además, a nivel externo, cuenta con una protección en frontera menor que la que percibe otras producciones comunitarias y, a nivel interno, es el sistema de retirada el único instrumento de intervención.

El sistema de retirada aparece como un mecanismo parco e insuficiente, en primer lugar porque no consiste en mantener la renta de los agricultores, sino cubrir una parte de los costes de producción evitando dejar los productos en el campo con el consiguiente impacto medioambiental que supone; además, las intervenciones de retiradas se sitúan en niveles más bajos que las establecidas en el análogo mecanismo anterior (precios de retirada). En segundo lugar, porque las ayudas percibidas son puramente coyunturales, ante deterioros acusados de los precios casi siempre ligados a situaciones de superproducción. En tercer lugar, estas ayudas se hallan desigualmente repartidas por dos motivos, uno porque es insuficiente el colectivo de agricultores que se benefician de ellas, sólo los productores integrados en OPFH (movilizan tan sólo el $50 \%$ de la producción del sector) las perciben en su integridad, los agricultores restantes sufren una reducción del 10\%; otro porque el 10\% de las OPFH se reparten casi el $50 \%$ de las mismas. En cuarto lugar, porque no todas las frutas y hortalizas las disfrutan, sólo cinco hortalizas (tomates, berenjenas, coliflores, melones y sandías), seis frutas no cítricas (manzanas, peras, albaricoques, melocotones, nectarinas y uvas de mesa) y cinco especies y variedades de cítricos 
(naranjas, limones, mandarinas, clementinas y satsumas) y con limitaciones en cuanto a volumen de producto a retirar, con una tendencia decreciente anualmente. Se empezó con porcentajes que oscilaban entre el 35 y 50\% para cítricos, frutas y hortalizas, a excepción de melones y sandías que se había fijado en el 10\%, situándose en la actualidad en un mínimo de un 5\% y un $10 \%$, respectivamente. Un último inconveniente se deriva de la demora por parte de la Administración en su pago: en Andalucía, por ejemplo, se abonaron en el año 2000 los importes de las retiradas efectuadas desde 1997 a 2000.

Los principales productos hortofrutícolas retirados anualmente en Andalucía son albaricoques, tomates, coliflores, naranjas, clementinas, limones y en menor medida, berenjenas y sandías. En la campaña 20062007 la intervención del mercado de frutas y hortalizas en esta región ha ascendido a 72,87 millones de euros, de los cuales el $41,89 \%$ ha correspondido al sudeste andaluz y el $37,4 \%$ a la provincia de Almería. El aumento o la disminución de productos acogidos al régimen de retirada cada año se debe, básicamente, a la sobreproducción que se registra, pero también atiende a otros factores como es el aumento de la competencia por parte de terceros países.

A pesar de estas críticas, desde otras esferas, se considera esta medida como necesaria ya que el sector hortofrutícola, orientado a obtener sus rentas del mercado y no de la salida institucional de las producciones y acostumbrado a desenvolverse en unas condiciones de máxima competitividad, precisa que los mecanismos públicos no incentiven el mantenimiento de estructuras poco competitivas, sino que sean reguladores de la oferta en momentos coyunturales para evitar hundimiento de precios, aunque se reclama la creación de un fondo especial para prevenir situaciones graves.

Un aspecto muy debatido últimamente es la integración de los países del Este Europeo a la UE. En principio las opiniones son positivas, por un lado, porque tendremos más fácil acceso a nuevos mercados anteriormente inaccesibles, de los que se espera que en un plazo de tiempo prudencial prosperen económica y socialmente, lo que inducirá a más de 100 millones de ciudadanos al consumo de frutas y hortalizas; por otro lado, porque su estructura productiva no va a entrar en competencia con las producciones mediterráneas, al estar orientadas en la línea de la producción de carácter continental. De cara a un futuro el verdadero competidor sería Turquía que aún no ha empezado a negociar su adhesión.

Dentro de este marco de relaciones institucionales sí es preocupante para el sector hortofrutícola los acuerdos preferenciales de la UE con terceros países. 
Estos acuerdos suponen una serie de medidas que suavizan el sistema de protección del mercado europeo frente a las importaciones procedentes de ellos, medidas que consisten en la exención o reducción del derecho arancelario, aplicado a un determinado volumen de importación (contingentes) o ser ilimitada. Debido a estos acuerdos, las ventajas comparativas que nuestras exportaciones pueden aprovechar del mercado de la UE (menor coste de producción y la climatología) no son tan claras frente a estos países con similar climatología y costes de producción más bajos.

La importancia de los acuerdos comerciales que la UE tiene firmado con terceros países se desprende del hecho de que el $61 \%$ de las importaciones de la Unión provienen de ellos. Los acuerdos más relevantes y que afectan más directamente al sector son los euromediterráneos, ya que con la Conferencia de Barcelona en 1995 se acordó crear una zona de libre comercio a ambas orillas del Mediterráneo para el año 2010. De estos países procede el $14,7 \%$ de las importaciones hortofrutícolas comunitarias. Los productos más sensibles son aquellos cuyas fechas de producción y comercialización coinciden en ambas orillas del Mediterráneo (tomates y cítricos), en el resto de productos (pepino, pimientos, calabacín, melón, sandía), las menores producciones de estos países, no han supuesto hasta el momento una clara amenaza (cuadro 7). Les siguen en importancia los acuerdos con los países que están dentro del Sistema de Preferencias Generalizadas (SPG) y los acuerdos con los países del Acuerdo de Cotonú, antiguo Acuerdo de Lomé (África, Caribe, Pacífico, ACP) de donde procede el $13,1 \%$ de las importaciones, donde los plátanos es el producto más delicado. Con menor repercusión están los acuerdos con los países de Sudamérica que viene a suponer el 27,4\% de las importaciones hortofrutícolas con especial incidencia del limón argentino, manzana chilena y últimamente los subtropicales.

El marco de las relaciones institucionales se completa con las directrices salidas del seno de la Organización Mundial del Comercio que pretende afianzar el proceso de liberalización del comercio mundial a través de la reducción de los aranceles hasta un máximo del $50 \%$ en productos como los tropicales. Las consecuencias de esta apertura son el incremento de las exportaciones de otros países a la UE, dado que se trata de uno de los mercados con mayor capacidad de compra y la aparición de un nuevo frente de competitividad en virtud de los bajos costes de producción como consecuencia del nivel salarial, de las cargas impositivas y otros factores de producción existentes en los países de procedencias (Sumpsi y Barceló, 1996). 


\begin{tabular}{|c|c|c|}
\hline Productos & Principales competidores & Acuerdos preferenciales \\
\hline Tomate & $\begin{array}{l}\text { Principal competidor: Marruecos. } \\
\text { También son productores: } \\
\text { Argelia, Chipre, Israel, Jordania, Malta, } \\
\text { Palestina y Túnez. }\end{array}$ & $\begin{array}{l}\text { Con todos los países posee acuerdos con } \\
\text { volúmenes ilimitados de entradas de } \\
\text { importaciones, a excepción de Israel } \\
\text { y Marruecos con quienes existen contingente, } \\
\text { aunque este último la rebasa continuamente, con } \\
\text { coincidencia de fechas de comercialización. }\end{array}$ \\
\hline Pimientos & $\begin{array}{l}\text { Turquía seguido de Egipto, Túnez } \\
\text { y Marruecos. }\end{array}$ & $\begin{array}{l}\text { En la actualidad no existen acuerdos comerciales } \\
\text { preferenciales. Las exportaciones no coinciden en } \\
\text { fechas. }\end{array}$ \\
\hline Melón & Turquía, Egipto y Marruecos. & Acuerdos con Israel y Marruecos. \\
\hline Sandía & Israel y Turquía. & Acuerdos preferenciales con ambos. \\
\hline Pepino & Turquía, Egipto, Israel y Marruecos. & $\begin{array}{l}\text { Acuerdos con Marruecos, aunque no supone pro- } \\
\text { blemas al no ser un gran productor ni exportador. }\end{array}$ \\
\hline Judías verdes & Egipto y Marruecos. & Sin acuerdo. \\
\hline Calabacín & Turquía. & Acuerdos con Turquía y Marruecos. \\
\hline Limón & Turquía y Egipto. & $\begin{array}{l}\text { Acuerdos con Chipre, Egipto, Marruecos, Túnez } \\
\text { y Turquía. }\end{array}$ \\
\hline Naranja & Marruecos e Israel. & Acuerdos con ambos. \\
\hline Aguacates & Israel y México. & Sin acuerdos preferenciales. \\
\hline
\end{tabular}

Fuente: Elaboración propia.

Este nuevo marco de relaciones internacionales obliga al sector hortofrutícola a aumentar sus niveles de competitividad, no ya sólo en los mercados exteriores, sino en los propios mercados internos ante la llegada de productos de otras áreas comerciales. En esta coyuntura no sólo se verán afectadas aquellas producciones que tradicionalmente han tenido problemas en el contexto comunitario por sus excedentes productivos (cítricos, hortalizas en periodos centrales de campañas, etc.), sino también aquellas que al no haberlos tenido nunca (frutales subtropicales) no contaron con la suficiente protección (sin precios de referencia y sin gravámenes compensatorios), lo que puede afectar a la estabilidad del sector.

En definitiva, nuevamente parece ser que uno de los sectores más competitivos de la agricultura española, el sector hortofrutícola, se va a enfrentar al proceso de liberalización del mercado mundial sin la protección suficiente y tendrá que afrontarla en base a sus capacidades intrínsecas de competitividad.

\section{CONCLUSIÓN: LAS INCERTIDUMBRES HACIA EL FUTURO}

El sistema productivo desarrollado en el sudeste andaluz ha situado a estas provincias en la vanguardia de la agricultura nacional e internacional, siendo la primera zona en producción y exportación de frutas y hortalizas en España. 
El dinamismo del sector hortofrutícola se ha manifestado en incrementos continuados de los rendimientos de los productos $(\mathrm{Tm} / \mathrm{ha}$ ) y de los ingresos de las explotaciones (€/ha). Tendencia que se ha mantenido hasta los primeros años de la década actual, cuando los rendimientos por hectáreas no compensan la bajada de los precios y nuevos elementos de incertidumbre se suman: continuo ascenso de los costes de producción, liberalización de los mercados internacionales, concentración de la distribución alimentaria y cambios en los hábitos de consumo de la población. Ante este conjunto de factores la hortifruticultura se enfrenta con incertidumbre al reto de armonizar estas demandas con la necesaria rentabilidad económica de las explotaciones.

El gran interrogante que se le plantea al sector es si la crisis será coyuntural, provocada por las grandes producciones que han incidido en rebajas de los precios o estructural, como consecuencia del aumento de los gastos por uso de tecnología obsoleta.

Deteniéndonos en la primera parte de este dilema hay que apuntar que las claves en las que se ha venido basando el dinamismo del sector no se pueden seguir manteniendo en un futuro. Continuar con incrementos productivos puede seguir incidiendo negativamente en las cotizaciones futuras de los productos y en la rentabilidad del sector.

Un primer aspecto que no aconseja mantener la situación precedente es el aumento de la oferta en la mayor parte de los mercados de destino donde confluye, tanto la procedente del litoral andaluz, como la de otras regiones españolas (Murcia-Levante), europeas y la de los terceros países.

Respecto a las producciones procedentes de terceros países, especial relevancia para el sector hortofrutícola son las procedentes de Marruecos e Israel, países con los que siempre determinadas producciones hortofrutícolas españoles (tomate, cítricos, aguacates) han tenido que competir en base a nuestra calidad y diferenciación. En el presente, la competitividad con estos países se acentúa por varios motivos, en primer lugar, por el continuo incremento de las importaciones de la UE desde estos terceros países, especialmente por parte de nuestros principales clientes (Francia, Alemania, Reino Unido); en segundo lugar, porque estos países están ampliando la gama de productos exportados, de forma que a los tradicionales se suman calabacines, pepinos, pimientos y judías verdes y, en tercer lugar, porque se puede ampliar la gama de países competidores como Turquía que, aunque hoy en día se caracteriza por la volatilidad de sus envíos hacia Europa, se presenta como un competidor en cítricos y hortalizas de cara a un futuro. 
Respecto a los países sudamericanos la competitividad no ha sido nunca muy intensa, debido al mercado de consumo que poseen en los países norteamericanos y a la posición geográfica respecto a los países europeos, si bien en las últimas campañas los aguacates procedentes de Chile y República Dominicana están entrando en el mercado europeo a través de las grandes comercializadores e hipermercados, provocando la consiguiente caída de los precios en origen.

En relación a las producciones procedentes de otras áreas españolas, en virtud de la extratemporalidad de las producciones del sudeste andaluz, la rivalidad competitiva se produce prioritariamente en la segunda parte de campaña, momento en que el litoral levantino posee ciertas ventajas comparativas respecto al andaluz basadas en su más ágil organización comercial y en su cercanía geográfica respecto a los mercados de destino. En el marco europeo, sin olvidar a Francia, Italia y Grecia, es Holanda el país que se configura como el principal competidor, su excelente localización, gestión del producto en invernadero y enorme tradición comercial le otorgan ventaja competitiva diferencial (Marín, 2004).

Un segundo aspecto que no contribuye a seguir en la línea del aumento de la productividad se sitúa del lado de la demanda por varios motivos, en primer lugar porque el consumo de frutas y hortalizas muestra signos de estabilidad, tanto en el marco nacional como internacional. En España, en el año 2006, el consumo de frutas retrocedió en 7 kg/persona/año (situándose en 103,3 kg/persona/año) y el de hortalizas en $5 \mathrm{~kg} /$ persona/año (situándose en 67,6 kg/persona/año). En el marco europeo, igualmente, desde finales de la década de los noventa, está estancando el consumo de frutas en $80,7 \mathrm{~kg} /$ persona/año y el de hortalizas en $69,1 \mathrm{~kg} /$ persona/año (Langreo, 2002). En segundo lugar porque los cambios operados en el comportamiento del consumidor europeo demandando productos sanos y naturales, presentados en diferentes formas (congelados, zumos, preparados naturales) y formatos (productos de IV y $\mathrm{V}$ gamas), obligan al sector a avanzar más en esta línea que en aumentos de producción.

Frente a este estancamiento de la demanda no es nada positivo el continuo incremento de los precios de venta al público de frutas y hortalizas, apreciándose una notable distancia entre los precios percibidos por los agricultores y los pagados por los consumidores debido a los abusos que se produce en la faceta de distribución comercial (mayorista-minorista) en los precios y márgenes que aplican. Si los bajos precios en origen, algunos de los cuáles ni siquiera cubren costos, se trasladaran a los consumidores, probablemente el consumo de frutas y hortalizas aumentara, evitando que a 
muchos agricultores les sea más rentable dejar pudrirse la cosecha en el campo que recolectarla. Más efectivo para reactivar el consumo que todas las campañas de publicidad (campaña de cinco al día) puestas en marcha, en los últimos años, por parte de la Administración y que no han dado los resultados esperados, sería controlar esta distorsión entre los precios de origen y destino en frutas y hortalizas estableciendo un coeficiente máximo entre el precio de compra al productor y el precio de venta al consumidor, de forma que cuando se rebasara se pusiera en marcha algún instrumento de control, tal y como ocurre en Francia.

Con respecto al segundo interrogante del dilema, el aumento de los costos de producción, hay que decir que hasta el momento no se ha realizado ningún esfuerzo por mejorar los ingresos de las explotaciones porque los márgenes de rentabilidad de los que gozaba el sector les permitían absorber los incrementos de los costes. Si bien, desde el momento en que el margen entre precio de producción del kilogramo de producto y precio de venta es tan estrecho, el sector no puede mantenerse indiferente. Son las deficiencias estructurales de las explotaciones las que se apuntan como otro responsable más de esta pérdida de rentabilidad del sector. Aunque esta afirmación no se puede extender a todo el universo de explotaciones, puesto que la diferencia de rentabilidad dependerá de la capacidad de cada agricultor de gestionar de forma eficaz su empresa, sí parece que está indisolublemente asociada al modelo de pequeña explotación con estructuras poco dotadas tecnológicamente con escasas posibilidades de reducir costes. En Almería, por ejemplo, aún el 40\% de la superficie invernada se basa en estructura de tipo parral (Fundación Cajamar, 2006).

De cara a un futuro, las opiniones más cualificadas del sector indican una tendencia hacia la consolidación de explotaciones empresariales de tamaño medio y grande, la modernización de estructura de producción con incorporación de avances tecnológicos y la gestión más eficaz de los recursos humanos invertidos (aumentar la productividad no tanto por unidad de superficie como por trabajador empleado) y no exclusivamente con aumentos productivos.

Ante esta situación la labor de las Administraciones Públicas es acompañar al sector en sus repuestas a los condicionantes anteriores, esto es, en su búsqueda de la competitividad. A nivel de la UE, como hemos apreciado, la relación entre la agricultura mediterránea y la UE se define como de desregulación y desprotección. En la historia de la UE la desprotección de la agricultura de los países del Sur ha sido una constante, 
habiéndose acentuado en los últimos tiempos cuando el marco de actuación comunitario en la agricultura cambió los objetivos marcados en los años cincuenta y empezó a cambiar los mecanismos de intervención. Hasta el momento ha sido la propia productividad del sistema agrícola intensivo la que ha permitido que sea prácticamente un sector desubsidiado y competitivo, pero los costes decrecientes que se vislumbran permite cuestionarse hasta cuándo la situación puede permanecer así, o en qué línea hay que actuar para no propiciar la situación más allá de unos límites razonables.

Recibido 16.05.08

Aceptado 22.10.08

\section{BIBLIOGRAFÍA}

Becattini, G. (1989): "Los distritos industriales y el reciente desarrollo italiano", Sociología del Trabajo, no 5, pp. 3-18.

Becattini, G. y Rullani, E. (1996): "Sistemas productivos locales y mercado global", Información Comercial Española, ICE, no 754, pp. 11-24.

Becattini, G. (2002): “Del distrito industrial marshalliano a la 'Teoría de distrito' contemporánea. Una breve reconstrucción crítica", Investigaciones regionales, nº 1, pp. 9-32.

Becattini, G. (2006): "Vicisitudes y potencialidades de un concepto: el distrito industrial", Economía Industrial, no 359, pp. 147-154.

Calatrava Requena, J. (1982): “Los regadíos del litoral mediterráneo andaluz. Realidad y problemática de una agricultura de vanguardia", Información comercial española, 582, pp. 67-87.

Calatrava Requena, J. (1985): "La horticultura litoral de primor en el contexto de la agricultura andaluza", Información Comercial Española, 619, pp. 1-95.

Caldenyey, P. y Gómez, A. (1996): "Productos típicos, territorios y competitividad", Agricultura y Sociedad, n 80/81, pp. 47-74.

Caldenyey, P. (1998): "El distrito agro-comercial del Campo de Dalías (España)", Agroalimentaria, $\mathrm{n}^{\circ} 7$, pp. 21-28.

Caldenyey, P. (2002): “Problemática de la comercialización de productos agrarios en Andalucía", Jornadas Autonómicas de Andalucía: El Libro blanco de la Agricultura y el Desarrollo Rural, Consejería de agricultura y pesca, Junta de Andalucía, Sevilla, pp. 1-38.

Carretero Gómez, A. (coord.) (2000): El sector industrial en la economía de Almería, Instituto de Estudios Almerienses, Diputación de Almería, Almería, 93 pp.

Climent López, E. (1997): "Sistemas productivos locales y distritos industriales: el caso de España", Boletín de la $A G E, \mathrm{n}^{\circ} 24$, pp. 91-106.

Ferraro Garcís, F.; Gámiz López, A.; Lucena Rodríguez, Y. y Verde Casanova, J. (2000): El sistema productivo almeriense y los condicionantes hidrológicos, Civitas, Madrid, 376 pp.

Fundación Cajamar (2006): Informe de la campaña hortofrutícola en Almería. Campaña 2005-06, Cajamar, Almería, 38 pp.

García Lorca, J. M. (1980): “La agricultura en el término de Níjar en el periodo 1960-1977. Análisis de su evolución y estudio de sus principales cultivos", Paralelo, 3, 4, pp. 25-40. 
García Lorca, J. M. (1985): “El caso de 'Tierras de Almería', una explotación de cultivos forzados en un contexto económico de empresa familiar agraria", Paralelo, 37, 8-9, 57-66.

García Lorca, J. M. (1999): "Tendencias y transformaciones de la agricultura intensiva almeriense", Ninbus, 4, pp. 109-128

García Manrique, E. (1972): Los cultivos subtropicales en la costa granadina, Universidad de Granada, 160 pp.

García Manrique, E. (1984): "Los nuevos paisajes agrarios. Los cultivos forzados", VII Coloquio de geógrafos españoles, Barcelona, pp. 99-132.

Hernández Porcel, M. C. (1978): "Balerma (Dalías) un área de cultivo enarenados", Paralelo, 37, 2, pp. 211-229

Hernádez Porcel, M. C. (1987): "La agricultura intensiva del Campo de Dalías", Paralelo, 3, 11-12, 133-140.

Junta de Andalucía (2002): Plan del sector hortícola de Almería, Consejería de Agricultura y Pesca, Junta de Andalucía, vol. 1, 51 pp.

Langreo Navarro, A. (2002): "Consumo de frutas y hortalizas en la Unión Europea. Innovación en la oferta y estrategias en la distribución", Distribución y Consumo, n 63, pp. 2435.

Larrubia Vargas, R. (1991): Producción y comercialización hortofrutícola en las comarcas costeras de Andalucía oriental, Universidad de Málaga, Tesis doctoral, 1735 pp.

Larrubia Vargas, R. (1995): “Agentes y empresas de comercialización que intervienen en la distribución de las producciones hortofrutícolas del litoral oriental andaluz", Baética, n ${ }^{\circ}$ 17, pp. 99-144.

Larrubia Vargas, R. (1998): La agricultura en Málaga a finales del siglo XX. Nuevas orientaciones productivas, Universidad de Málaga, Málaga, 237 pp.

Marín Carrillo, G.; Marín Carrillo, M. B. y Jiménez Castillo, D. (2004): “Análisis de las fuerzas competitivas del sector agrícola de Almería", Boletín Económico del ICE, n 2798, 47 59.

Ministerio de Agricultura, Pesca y Alimentación (2003): El libro blanco de la agricultura y el desarrollo rural, MAPA, Madrid.

Ministerio de Agricultura, Pesca y Alimentación (2004): Informe del sector frutas y hortalizas (oferta, distribución y demanda), MAPA, Madrid, 141 pp.

Ministerio de Agricultura, Pesca y Alimentación (2006): Hechos y cifras del la agricultura, la pesca y la alimentación en España, MAPA, Madrid, 159 pp.

Molina Herrera, J. y García Torrente, R. (2002): "Situación actual y perspectivas de futuro de la horticultura intensiva en el litoral andaluz", Jornadas Autonómicas de Andalucía: El Libro blanco de la Agricultura y el Desarrollo Rural, Consejería de Agricultura y Pesca, Junta de Andalucía, Sevilla, pp. 1-23.

Palao Taboada, F. y Salinas Andújar, J. (2007): Potencialidad del transporte hortofutícola por el Puerto de Almería, Universidad de Almería, 340 pp.

Sumpsi Viñas, J. M. y Barcelo Vila, L. V. (1996): La Ronda de Uruguay y el sector agroalimentario español,Ministerio de Agricultura, Pesca y Alimentación, Serie Estudios, Madrid, 816 pp., en: http://www.lavozdealmeria.com

\section{Resumen}

El sector hortofrutícola del sudeste andaluz es uno de los más significativos distritos de producción hortofrutícola de España. El modelo agronómico desarrollado ha basado su dinamismo en continuas ganancias de productividad y en la proyección exterior de la producción. En la actualidad, el sector vive una creciente preocupación por el descenso de la rentabilidad de los productores, debido al incremento de los costes de producción que no van acompañados por un aumento proporcional tanto de la productividad, como de los precios de los productos hortofrutícolas. En consonancia con estos planteamientos, se analiza la 
estructura productiva del sector poniendo el acento en la evolución reciente de rendimientos, costes y exportación, sin olvidar el impacto que sobre el sector posee las regulaciones agrícolas internacionales y los elementos que apoyan su identificación como distrito industrial.

Palabras clave: rentabilidad; rendimientos; competitividad; distrito agroindustrial; exportación.

\begin{abstract}
The fruit and vegetable sector of southeastern Andalusia is one of the most important districts of fruit and vegetable production in Spain. The dynamism of the agronomic model developed is based on the constant increase of productivity and the exterior projection of production. At present, the sector is increasingly concerned about the decrease of producer profitability, due to increased production costs which are not followed by a proportional increase of productivity and of fruit and vegetable prices. In keeping with this situation, the productive structure of the sector is analysed, focusing on the recent evolution of yields, costs and exports, without forgetting the impact caused in the sector by international farming regulations and by the elements in favour of identifying it as an industrial district.
\end{abstract}

Key words: profitability; yields; competitiveness; agroindustrial district; export. 